\title{
Investigation of the Effective Catalyst for Organosolv Pretreatment of Liriodendron tulipifera*1
}

\author{
Bon-Wook Koo*2, Ki-Seob Gwak ${ }^{* 2}$, Ho-Yong Kim ${ }^{* 2}$, Joon-Weon Choi ${ }^{* 2,3}$, \\ Hwanmyeong $\mathrm{Yeo}^{* 2,3}$, and In-Gyu Choi ${ }^{* 2,3+}$
}

\begin{abstract}
Organosolv pretreatments which utilized sulfuric acid, sodium hydroxide and ammonia as catalysts were conducted to screen the effective catalyst for organosolv pretreatment of Liriodendron tulipifera. The enzymatic hydrolysis was achieved effectively with sulfuric acid (74.2\%) and sodium hydroxide (63.7\%). They were thus considered as effective catalysts for organosolv pretreatment of L. tulipifera. The organosolv pretreatments with sulfuric acid and sodium hydroxide showed a different behavior on the reaction mechanism. The pretreatment with sulfuric acid increased the biomass roughness and pore numbers. On the other hand, the pretreatment with sodium hydroxide enhanced the surface area due to the size reduction and minor defiberization which were caused by hemicellulose degradation at an initial stage and more defiberization by lignin degradation at a later stage. The organosolv pretreatment with sodium hydroxide was performed at several different conditions to evaluate effectiveness of sodium hydroxide as a catalyst for organosolv pretreatment. According to the results of enzymatic digestibility, the changes of chemical composition and the morphological analysis of pretreated biomass, it was suggested that the pretreatment time impacted primarily on enzymatic hydrolysis. Increase in surface area during the pretreatment was a major cause for improvement in enzymatic digestibility when sodium hydroxide was used as a catalyst.
\end{abstract}

Keywords : Liriodendron tulipifera, organosolv pretreatment, sulfuric acid catalyst, sodium hydroxide catalyst, enzymatic hydrolysis

\section{INTRODUCTION}

Current corn-based ethanol has many problems such as technical maturity [1], a limitation in feedstock supply [2] and low environmental effect by only 20 to $40 \%$ of carbon dioxide reduction [3]. Also, it would compete with food and feed market and using a synthesized fertilizer for improving the yield of corn production can contribute to global warming.

*1 Received on February 2, 2010; accepted on March 10, 2010

*2 Department of Forest Sciences, College of Agriculture and Life Sciences, Seoul National University, Seoul 151-921, Korea

*3 Research Institute for Agriculture and Life Sciences, College of Agriculture and Life Sciences, Seoul National University, Seoul 151-921, Korea

† Corresponding author : In-Gyu Choi (e-mail: cingyu@snu.ac.kr) 
For these reasons, many alternative resources for bioethanol production have been studied, and lignocellulosic biomass which consists of abundant carbohydrates has been interested as a new resource for bioethanol production [4,5].

However, a complex structure of lignocellulosic biomass causes difficulties in converting biomass to fermentable sugar. Therefore, an effective pretreatment process which facilitates biomass conversion is required for efficient cellulosic ethanol production [6].

The development of effective pretreatment technology is the primary challenge for the commercialization of cellulosic ethanol [7-9]. Various pretreatment methods have been studied to improve fermentable sugar yield in cellulosic ethanol production process $[9,10]$. However, most researches were focused on low-lignin containing lignocellulosic biomass such as corn stover and switch grass, therefore, the effective and customized pretreatment method must be developed for high-lignin containing lignocellulosic biomass.

At present, organosolv pretreatment based on ethanol is being evaluated as an efficient technology for woody biomass [11-13] because it was investigated as a pulping process for woods [14-16]. Additionally, several researchers have investigated on lignin fraction during the pretreatment [17], and the generation of potentially valuable co-products such as high-quality lignin and their possible contributions to cost-effective biorefinery schemes for cellulosic bioethanol production [18]. However, the organosolv process has not been extensively studied as a pretreatment process for producing cellulosic ethanol [19].

In organosolv pretreatment, an aqueous organic solvent and an inorganic acid catalyst are usually used to break down internal lignin and hemicellulose bonds [20]. Hydrochloric acid and sulfuric acid have been utilized as inorganic cat- alysts, and they are effective for the pretreatment of lignocellulosic biomass. However, they are very toxic and hazardous, thus resulting in certain environmental problems. Further, using the acid catalyst requires neutralization of pretreated biomass for downstream biological processes because of the formation of inhibitory compounds such as acetic acid and furfural in the hydrolysate [5]. Alkalis such as sodium hydroxide, ammonia and lime have been used as well for the pretreatment of lignocellulosic biomass since they can effectively remove lignin [10,21].

In this study, sulfuric acid and sodium hydroxide were applied as the inorganic acid and alkali catalyst, and ammonia which has been used as a chemical for pretreatment as well was also applied to screen the effective catalyst. Pretreated biomass was enzymatic hydrolyzed and the organosolv pretreatment process depending on catalysts was evaluated by determination of enzymatic digestibility.

For the materials, Liriodendron tulipifera was utilized. It can easily adjust to a variety of climates and soil conditions, and is tolerant to damages by harmful insects. It has a short cut-down period and grows straight and thick, so it might be valuable as a lignocellulosic biomass in Korea. Furthermore, it also has an exceptional sequestration capacity for carbon dioxide. Thus, it has been officially recommended for afforestation in Korea, and an amount of biomass production is being expected at present.

\section{MATERIALS and METHODS}

\subsection{Materials}

Logs of L. tulipifera (20 years old) were collected at the Forest Human Resources Development Institute, Korea Forest Services. The logs were ground and sieved through a 40-mesh 
screen. The ground woods were air-dried, and the moisture content was reduced less than $10 \%$. The initial composition of L. tulipifera was determined as $41.1 \%$ of glucan, $21.2 \%$ of xylan, $2.5 \%$ of arabinan, $0.2 \%$ of mannan, $0.9 \%$ of galactan, $21.4 \%$ of Klason lignin, $2.1 \%$ of acid soluble lignin, $0.3 \%$ of ash and $4.2 \%$ of extractives.

\subsection{Organosolv Pretreatment}

The reactor consisted of a minibomb (Bolted closure Vessels, Ilshin Autoclave Co. Ltd., Korea) which was manufactured with stainless steel (STS316). Its diameter and height were 10 $\mathrm{cm}$ and $30 \mathrm{~cm}$, respectively, and an internal reactor was made of Teflon with a $500 \mathrm{ml}$ capacity. Teflon-sealed closure system was applied to maintain the reaction pressure during pretreatment, and the pretreatment temperature was controlled by an external controller.

The ratio of materials and aqueous ethanol $(50 \%)$ was set at $1: 20(10 \mathrm{~g} / 200 \mathrm{~m} \ell)$ and catalysts were added to the mixture. The mixture of aqueous ethanol and materials without catalyst was also tried to investigate the effect of solvent. $1 \%(\mathrm{w} / \mathrm{w})$ of sulfuric acid and $1 \%(\mathrm{w} / \mathrm{w})$ of sodium hydroxide were applied as catalysts and $5 \%$ of ammonia (w/w) was used for the catalyst. Pretreatment time was recorded after inserting the reactor in the heating mantle which was preheated at the target temperature. After pretreatment, the reactor was immediately transferred into ice chamber to cool down at room temperature. Pretreatments were conducted at $180^{\circ} \mathrm{C}$ and $200^{\circ} \mathrm{C}$ for 30 and $60 \mathrm{~min}$. Pretreated mixtures were washed with distilled water sufficiently and filtrated by using a fritted glass filtering crucible (2G2 Iwaki, Japan). Finally, pretreated mixtures were divided into the pretreated biomass (wet solid fractions) and liquid fraction (water soluble and water insoluble fractions).
Used ethanol was recovered by a rotary evaporator.

After screening of the effective catalyst, pretreatments with sodium hydroxide were conducted at various conditions to evaluate the effectiveness of alkaline catalyst for organosolv pretreatment. Concentrations of sodium hydroxide were $0.5,1$ and $2 \%(\mathrm{w} / \mathrm{w})$, and the pretreatments were conducted at $140^{\circ} \mathrm{C}, 160^{\circ} \mathrm{C}, 180^{\circ} \mathrm{C}$ and $200^{\circ} \mathrm{C}$ for 60 or $90 \mathrm{~min}$.

\subsection{Enzymatic Hydrolysis}

A commercial cellulase from Tricoderma viride, Meicelase (Meiji Seika Co., Ltd., Tokyo, Japan) was used for the enzymatic hydrolysis. Enzymatic hydrolysis was performed with $1 \mathrm{~g}$ of pretreated biomass in $100 \mathrm{ml}$ of $50 \mathrm{mM}$ acetate buffer ( $\mathrm{pH} \mathrm{5.0)}$ containing $40 \mathrm{mg}$ of the enzyme powder which had 9 FPU of cellulase activity and $11 \mathrm{IU}$ of $\beta$-glucosidase activity. The mixtures were incubated at $45^{\circ} \mathrm{C}$ in a rotary shaker at $250 \mathrm{rpm}$ and the same procedure was also applied to the control (untreated raw biomass) [22]. The enzymatic digestibility was determined in duplicate, and it was defined as the percentage of enzymatically hydrolyzed biomass based on dried-pretreated biomass after $48 \mathrm{hr}$ of incubation.

\subsection{Chemical Composition}

Contents of holocellulose, $\alpha$-cellulose and Klason lignin were determined. The content of holocellulose was determined as the delignified residue by $\mathrm{NaClO}_{2}$, and that of $\alpha$-cellulose was determined as the insoluble residue in $17.5 \%$ of $\mathrm{NaOH}$ solution. These analyses were performed according to the TAPPI test methods. Klason lignin was analyzed according to the standard NREL procedures [23] and its content was defined as the amount of retained residue after 


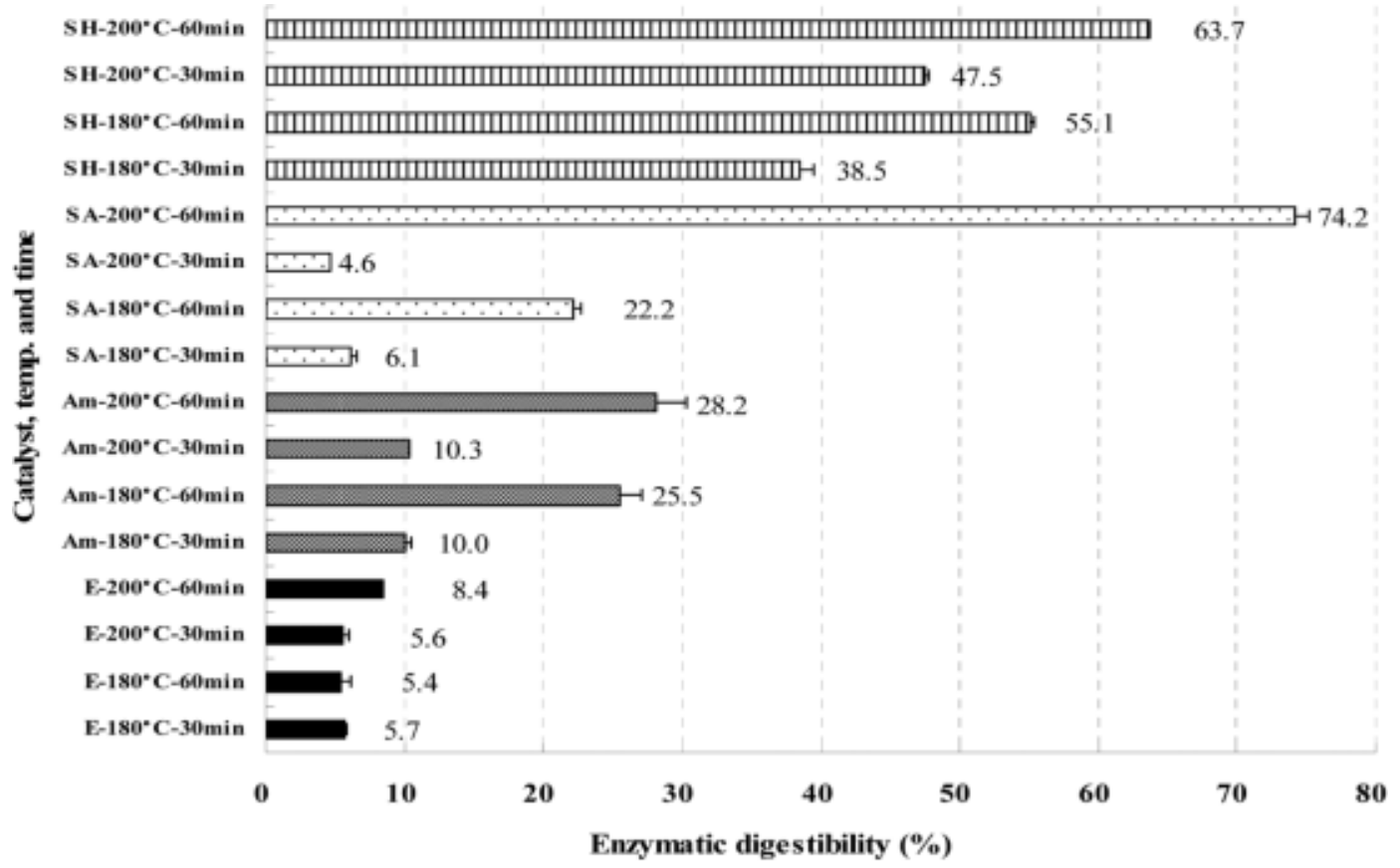

Fig. 1. Enzymatic digestibility depending on catalysts and pretreatment conditions. E: Ethanol only; Am: Ammonia catalyst; SH: Sodium hydroxide catalyst; SA: Sulfuric acid catalyst.

following two step sulfuric acid hydrolysis (72\% and $4 \%$ ). $0.3 \mathrm{~g}$ of biomass was hydrolyzed in $25 \mathrm{~m} \ell$ flasks with $3 \mathrm{~m} \ell$ of $72 \%$ sulfuric acid at $30^{\circ} \mathrm{C}$ for $1 \mathrm{hr}$. The hydrolysate was then transferred to $100 \mathrm{~m} \ell$ flask and diluted to $4 \%$ of sulfuric acid by adding $84 \mathrm{~m} \ell$ of deionized water. The flasks were sealed and autoclaved for $1 \mathrm{hr}$ at $121^{\circ} \mathrm{C}$. The solution was then filtrated by using a fritted glass filtering crucible (1G4 Iwaki, Japan). The filtrated residue was dried at $105 \pm$ $1^{\circ} \mathrm{C}$ and then weighed.

\subsection{Cellulose Crystallinity}

Cellulose crystallinity was measured by the X-ray diffractometer (Bruker D5005, Germany) operated at $40 \mathrm{Kv}$ and $40 \mathrm{~mA}$. The diffraction spectra were taken by $\theta-2 \theta$ method and duplicate samples were scanned at $1 \%$ min from 2 $\theta=10^{\circ} \sim 30^{\circ}$ with a step of $0.01^{\circ}$. Relative crystalline index was calculated according to the Segal's method [24].

\subsection{Morphological Analysis}

Microscopic analysis was performed to investigate the morphological changes of biomass by the pretreatment. The morphology of pretreated biomass was examined by field-emission scanning electron microscopy (FE-SEM, SUPRA 55VP, Carl Zeiss, Germany). Pretreated biomass was prepared for imaging by freeze-drying. For the analysis of FE-SEM, the samples were mounted on aluminum stubs using carbon tape with conductive silver paint applied to the sides to reduce sample charging and then sputtercoated with Pt-Pd by sputter coater. Imaging was performed at $3 \mathrm{kV}$ of beam voltages [25]. 


\section{RESULTS and DISCUSSION}

\subsection{Enzymatic Digestibility Depending on Catalyst}

All pretreatments using catalyst improved the enzymatic digestibility compared to the digestibility of untreated biomass $(9.0 \%)$. However, pretreatment using ethanol only without catalyst could not improve the digestibility regardless of pretreatment conditions. When $1 \%$ of sulfuric acid, a typical catalyst for organosolv pretreatment, was utilized, enzymatic digestibility ranged from $4.6 \%$ to $74.2 \%$ based on pretreated biomass (Fig. 1). The highest digestibility was obtained from the pretreated biomass at $200^{\circ} \mathrm{C}$ for $60 \mathrm{~min}$ and it was higher than the digestibility by dilute acid pretreatment without organic solvent [26]. Wyman and co-worker reported that $83 \%$ of sugar was recovered totally after enzymatic hydrolysis from poplar wood pretreated by dilute acid however we could recover 95\% of total sugar based on carbohydrates in pretreated biomass. Therefore, it was speculated that organo-solvent facilitate the catalyst reaction on biomass during the pretreatment. Enzymatic digestibility of the pretreated biomass with $1 \%$ of sodium hydroxide improved significantly compared to the control. It ranged from $38.5 \%$ to $63.7 \%$ based on pretreated biomass, with the highest obtained at $200^{\circ} \mathrm{C}$ for $60 \mathrm{~min}$. The highest digestibility could be calculated at $84 \%$ of total sugar recovery based on carbohydrates in pretreated biomass. It was higher than Huffman and co-worker's resulting $72 \%$ sugar recovery with 4\% sodium hydroxide [27]. Both sulfuric acid and sodium hydroxide significantly improved digestibility; consequently, they could be used as the effective catalysts for organosolv pretreatment. Ammonia has been also recognized as an effective chemical for delignification, and many studies on ammonia pretreatment were conducted [28-33]. When 5\% (w/w) of ammonia was used as a catalyst for organosolv pretreatment in this study, the highest enzymatic digestibility was just $28.2 \%\left(200^{\circ} \mathrm{C}\right.$ for $\left.60 \mathrm{~min}\right)$. It was less than the result of the ammonia pretreatment without an organo-solvent [31]. Therefore, ammonia was not considered as an effective catalyst for organic pretreatment of $L$. tulipifera. Organosolv pretreatment without any catalyst could not improve digestibility; consequently, the catalyst must be applied to improve digestibility.

Based on the results, $1 \%$ of sulfuric acid and sodium hydroxide were determined as effective catalysts for organosolv pretreatment, therefore both of them were applied for further study.

\subsection{Change of Chemical Composi- tions}

Both organosolv pretreatments decreased amorphous cellulose and lignin contents regardless of catalyst, and little difference in chemical composition depending on catalyst was determined. The $\alpha$-cellulose (crystalline cellulose) ratio significantly increased and a minor decrease in lignin content compared to the untreated biomass was confirmed (Fig. 2). The contents of holocellulose, $\alpha$-cellulose, and lignin in pretreated biomass were determined as 78.0, 54.5, and 16.5 $\mathrm{wt} \%$, respectively, when using sulfuric acid catalyst, and 75.6, 53.3, and $17.2 \mathrm{wt} \%$, respectively, when using sodium hydroxide.

Although a large amount of lignin degradation was expected during pretreatment due to the alkaline catalyst and high temperature at $200^{\circ} \mathrm{C}[34,35]$, lignin content in pretreated biomass with sodium hydroxide was similar with sulfuric acid. It was considered that the insoluble was formed by the linkage of shorter-chained form lignin fragment released during the pretreatment with alkaline catalyst and hem- 


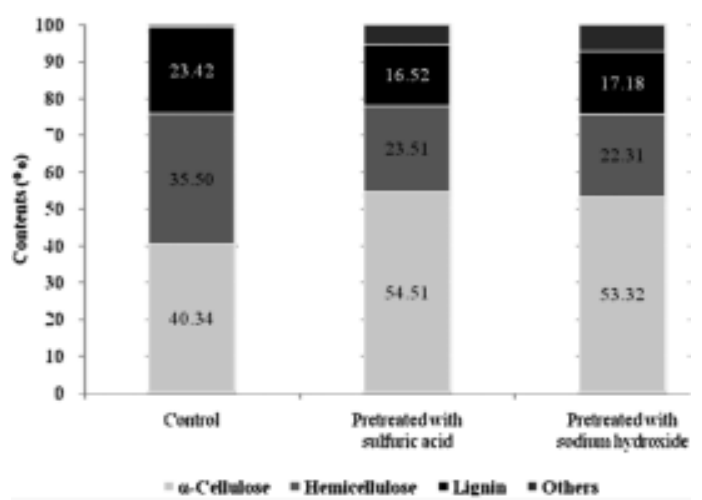

Fig. 2. Chemical compositions of L. tulipifera. All pretreatments were performed at $200^{\circ} \mathrm{C}$ for 60 min with $1 \%$ catalyst concentration.

icellulose oligomer and monomer and this insoluble content was determined for lignin content [36].

\subsection{Cellulose Crystallinity}

Although the chemical compositions of pretreated biomass achieved by means of sulfuric acid and sodium hydroxide were similar, cellulose crystallinity varied depending on the catalyst (Fig. 3). The crystallinity of pretreated biomass with sulfuric acid (60.4\%) increased compared to the control $(54.5 \%)$ due to the preferential degradation of the amorphous region during the pretreatment with sulfuric acid. However, the crystallinity of pretreated biomass with sodium hydroxide $(53.6 \%)$ was not increased because pretreatment with sodium hydroxide degraded not only the amorphous region but other components such as lignin as well [10]. Many researchers reported that crystallinity correlated inversely with enzymatic digestibility [37-39], but a number of reports claimed that crystallinity did not correlate with enzymatic digestibility [40-42]. The conflicting results is caused by relative value which is determined by the XRD.

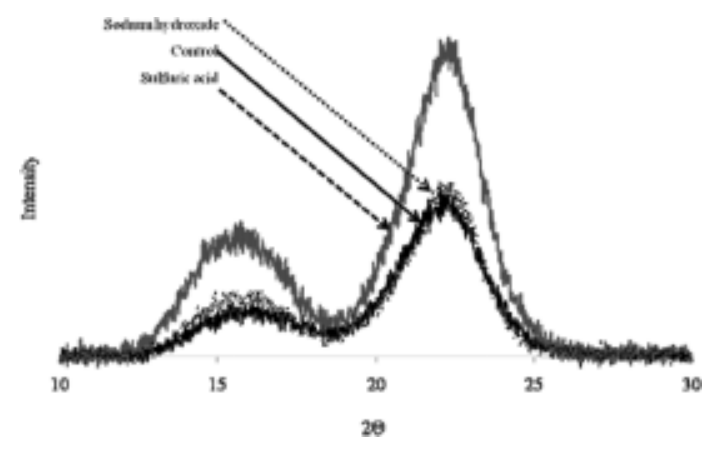

Fig. 3. Cellulose crystallinity of L. tulipifera. All pretreatments were performed at $200^{\circ} \mathrm{C}$ for 60 min with $1 \%$ catalyst concentration.

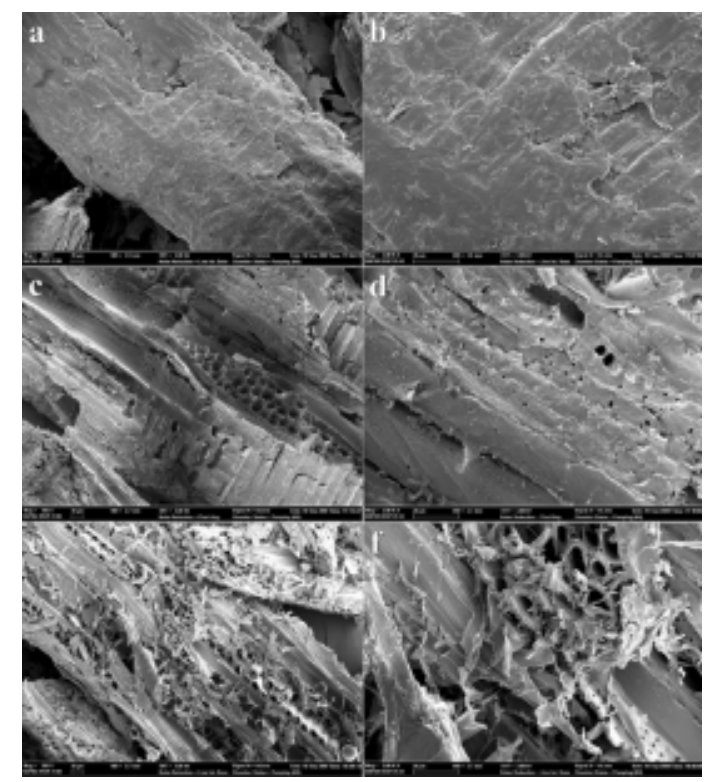

Fig. 4. FE-SEM images of L. tulipifera. a, b: control; c, d: pretreated with sulfuric acid; e, f: pretreated with sodium hydroxide. Allpretreatments were performed at $200^{\circ} \mathrm{C}$ for $60 \mathrm{~min}$ with $1 \%$ catalyst concentration.

\subsection{Morphological Analysis (FE-SEM)}

Fig. 4 illustrates the morphological surface structure of the control and pretreated biomasses determined by FE-SEM. As the surface of un- 

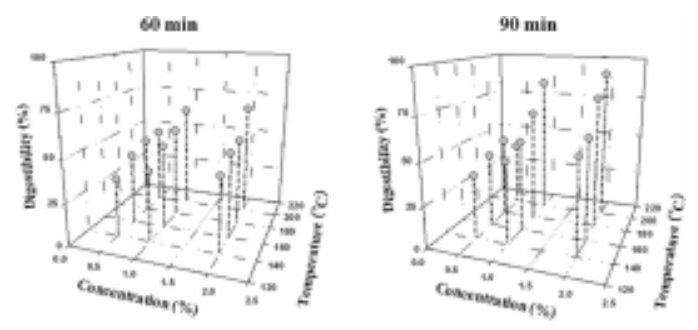

Fig. 5. Enzymatic digestibility of L. tulipifera by organosolv pretreatment with sodium hydroxide.

treated biomass was very sleek and solid $(a, b)$, which might be inaccessible to cellulase, therefore the enzymatic hydrolysis was not improved [43]. However, the surface structures of both pretreated biomass were not sleek and solid. The increase in the surface roughness and pores by hemicellulose degradation was observed on the surface of pretreated biomass with sulfuric acid (c, d). This could possibly improve the accessibility of cellulase to cellulose. Pretreated biomass with sodium hydroxide showed the defiberization and formation of small pieces due to lignin and hemicellulose degradation (e, f), otherwise the formation of pores was not observed. Consequently, it was considered that pretreatment with sodium hydroxide improved enzymatic digestibility by increasing surface area through defiberization and breaking into small pieces.

\subsection{Organosolv Pretreatment with Sodium Hydroxide at Various Conditions}

\subsubsection{Enzymatic Digestibility}

It was determined that sulfuric acid and sodium hydroxide were effective catalysts for the organosolv pretreatment of L. tulipifera. However, sulfuric acid has been used as a common catalyst for organosolv pretreatment while sodium hydroxide did not; therefore, organosolv pre- treatment with sodium hydroxide was performed under various conditions to evaluate the effectiveness of sodium hydroxide as a catalyst. Pretreatments were conducted at $140^{\circ} \mathrm{C}, 160^{\circ} \mathrm{C}$, $180^{\circ} \mathrm{C}$, and $200^{\circ} \mathrm{C}$ for 60 or $90 \mathrm{~min}$ and $0.5 \%$, $1 \%$ and $2 \%$ of sodium hydroxide $(\mathrm{w} / \mathrm{w})$ were used as catalyst, respectively.

Enzymatic digestibility improved by increasing pretreatment time, temperature, and catalyst concentration (Fig. 5). However, a little difference in enzymatic digestibility was determined depending on sodium hydroxide concentration more than $1 \%$, otherwise, the increase in pretreatment temperature and pretreatment time improved the enzymatic digestibility dramatically, therefore they were considered as the major factor affecting the enzymatic hydrolysis.

\subsubsection{Analysis of Pretreated Biomass De- pending on Pretreatment Time}

Chemical composition of pretreated biomass depending on pretreatment time was analyzed to investigate the behavior of organosolv pretreatment with sodium hydroxide. Pretreatment temperature and sodium hydroxide concentration were fixed at $200^{\circ} \mathrm{C}$ and $2 \%$, respectively, and the pretreatments were performed for 30,60 , and $90 \mathrm{~min}$.

Table 1 illustrates the chemical composition and enzymatic digestibility of pretreated biomass depending on pretreatment time. Morphological analysis using FE-SEM was shown in Fig. 6. Based on these results, breaking into small pieces and defiberization were preceded simultaneously at an initial stage (b, $30 \mathrm{~min})$; it could improve enzymatic digestibility by increasing surface area for enzyme adsorption. As pretreatment time increased, lignin degradation caused further defiberization and increase in surface area (d, $90 \mathrm{~min}$ ). Therefore, it could be concluded that the organosolv pretreatment with sodium hydroxide improved the digestibility 
Bon-Wook Koo, Ki-Seob Gwak, Ho-Yong Kim, Joon-Weon Choi, Hwanmyeong Yeo, and In-Gyu Choi

Table 1. Chemical Compositionand Enzymatic Digestibility of L. tulipifera by the Organosolv Pretreatment with Sodium Hydroxide Dependingon Pretreatment Time

\begin{tabular}{cccccc}
\hline Pretreatment Time & $\alpha$-Cellulose (\%) & Hemicellulose (\%) & Lignin (\%) & Others (\%) & Digestibility* (\%) \\
\hline \hline Control & $40.3 \pm 0.4$ & $35.5 \pm 0.4$ & $23.4 \pm 0.2$ & $0.8 \pm 0.6$ & $9.0 \pm 0.7$ \\
$30 \mathrm{~min}$ & $48.9 \pm 0.3$ & $23.6 \pm 0.3$ & $21.3 \pm 0.1$ & $6.2 \pm 0.4$ & $38.2 \pm 0.1$ \\
$60 \mathrm{~min}$ & $56.2 \pm 0.5$ & $19.2 \pm 0.5$ & $18.7 \pm 0.1$ & $5.9 \pm 0.6$ & $70.4 \pm 0.2$ \\
$90 \mathrm{~min}$ & $71.0 \pm 2.5$ & $17.7 \pm 2.5$ & $8.3 \pm 0.3$ & $2.9 \pm 2.8$ & $96.4 \pm 0.5$ \\
\hline
\end{tabular}

* All pretreatments were performed at $200^{\circ} \mathrm{C}$

* All value were calculated onoven-dried pretreated biomass

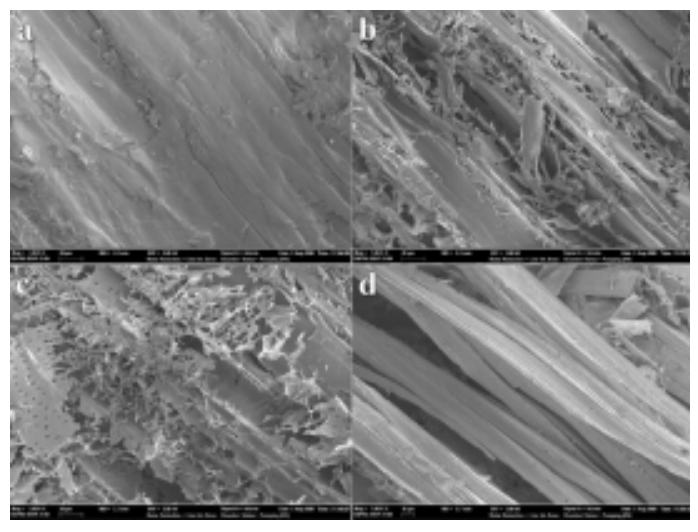

Fig. 6. FE-SEM images of L. tulipifera by organosolv pretreatment with sodium hydroxide. a: control; b: pretreated for $30 \mathrm{~min}$; c: pretreated for $60 \mathrm{~min}$; d: pretreated for $90 \mathrm{~min}$.

through the increase in surface area by breaking into small pieces and defiberization, which were caused by hemicellulose degradation at an initial stage; and lignin degradation at a later stage. It also explained why the organosolv pretreatment with sodium hydroxide improved the digestibility regardless of pretreatment temperature and time unlike sulfuric acid catalyst which improved the digestibility at specific condition (Fig. 1).

\section{CONCLUSIONS}

In order to screen the effective catalyst for organosolv pretreatment of $L$. tulipifera, sulfuric acid, sodium hydroxide, and ammonia were applied as catalysts. Sulfuric acid and sodium hydroxide were considered as effective catalysts for the organosolv pretreatment of L. tulipifera. However, the pretreatment behaviors of each catalyst revealed a different aspect. The increase in roughness and pore numbers by hemicellulose degradation improved the enzymatic hydrolysis by the pretreatment with sulfuric acid. On the other hand, the pretreatment with sodium hydroxide improved the enzymatic hydrolysis by increasing surface area through breaking into small pieces and defiberization caused by hemicellulose and lignin degradation.

As the result of organosolv pretreatment with sodium hydroxide under various conditions, pretreatment temperature and time were the major factors affecting enzymatic hydrolysis in organosolv pretreatment with sodium hydroxide. However, catalyst concentration scarcely affected enzymatic digestibility when it was above $1 \%$. The analysis and enzymatic hydrolysis of pretreated biomass indicated that the organosolv pretreatment with sodium hydroxide increased the surface area by breaking into small pieces and defiberizing, which were caused by hemicellulose degradation at an initial stage and lignin degradation at a later stage. Finally, the increased surface area improved enzymatic digestibility. 


\section{ACKNOWLEDGEMENT}

This study was carried out with the support of 'Forest Science \& Technology Projects (Project No. S120809L140130)' provided by Korea Forest Service and 'Cooperative Research Program for Agricultural Science \& Technology Development (Project No. 20090101-036-006-001-04-00)' provided by RDA, Republic of Korea.

\section{REFERENCES}

1. Ingram, L. O. and J. B. Doran. 1995. FEMS Microbiology Reviews 16: 235 241.

2. Gray, K. A., L. Zhao, and M. Emptage. 2006. Current Opinion in Chemical Biology 10: 141 146.

3. Fulton, L., T. Howes, and J. Hardy. 2004. Biofuels for transport: an international perspective, OECD, International Energy Agency.

4. Söderström, J., L. Pilcher, M. Galbe, and G. Zacchi. 2003. Biomass and Bioenergy 24: $475 \sim 486$.

5. Sun, Y. and J. Cheng. 2002. Bioresource Technology 83: $1 \sim 11$.

6. Saddler, J. N., L. P. Ramos, and C. Breuil. 1993. CAB International, London, UK 73 92.

7. Lynd, L. R., P. J. Weimer, W. H. van Zyl, and I. S. Pretorius. 2002. Microbiology and Molecular Biology Reviews 66: 506 577.

8. Mosier, N., C. Wyman, B. Dale, R. Elander, Y. Y. Lee, M. Holtzapple, and M. Ladisch. 2005. Bioresource Technology 96: 673 686.

9. Wyman, C. E., B. E. Dale, R. T. Elander, M. Holtzapple, M. R. Ladisch, and Y. Y. Lee. 2005. Bioresource Technology 96: 1959 1966.

10. McMillan, J. D. 1994. The ACS Symposium Series 566: 292 324 .

11. Pye, E. K. and J. H. Lora. 1991. TAPPI Journal 74.

12. Stockburger, P. 1993. Tappi Journal (USA) 76: $71 \sim 74$.

13. Chum, H. L., D. K. Johnson, and S. K. Black. 1990. Industrial \& Engineering Chemistry Research 29: $156 \sim 162$.

14. Diaz, M. J., A. Alfaro, M. M. Garcia, M. E.
Eugenio, J. Ariza, and F. Lopez. 2004. Industrial \& Engineering Chemistry Research 43: 1875 1881.

15. Jimenez, L., I. Perez, J. C. Garcia, A. Rodriguez, and J. L. Ferrer. 2002. Process Biochemistry 37: $665 \sim 672$.

16. Chum, H. L., D. K. Johnson, S. Black, J. Baker, K. Grohmann, and K. V. Sarkanen. 1998. Biotechnology and Bioengineering 31: 643 649.

17. Liu, Y., S. Carriero, K. Pye, and D. S. Argyropoulos. 2000. A comparison of the structural changes occurring in lignin during Alcell and kraft pulping of hardwoods and softwoods, American Chemical Society, USA, Washington DC.

18. Pan, X., C. Arato, N. Gilkes, D. Gregg, W. Mabee, K. Pye, Z. Xiao, X. Zhang, and J. Saddler. 2005. Biotechnology and Bioengineering 90: 473 481.

19. Pan, X., N. Gilkes, J. Kadla, K. Pye, S. Saka, D. Gregg, K. Ehara, D. Xie, D. Lam, and J. Saddler. 2006. Biotechnology and Bioengineering 94: 851 $\sim 861$.

20. Holtzapple, M. T. and A. E. Humphrey. 1984. Biotechnology and Bioengineering 26: 670 676.

21. Fan, L. T., M. M. Gharpuray, and Y. H. Lee. 1987. Cellulose hydrolysis. Biotechnology monographs, Springer-Verlag, USA, New York.

22. Teramoto, Y., N. Tanaka, S. H. Lee, and T. Endo. 2008. Biotechnology and Bioengineering 99: $75 \sim 85$.

23. NREL. 2005. Biomass Analysis Technology Team Laboratory Analytical Procedure, US Department of Energy, National Renewable Energy Laboratory, Golden, CO.

24. Segal, L., J. J. Creely, A. E. Martin Jr, and C. M. Conrad. 1959. Textile Research Journal 29: 786.

25. Donohoe, B. S., S. R. Decker, M. P. Tucker, M. E. Himmel, and T. B. Vinzant. 2008. Biotechnol Bioeng 101: 913 925 .

26. Wyman, C. E., B. E. Dale, R. T. Elander, M. Holtzapple, M. R. Ladisch, Y. Y. Lee, C. Mitchinson, and J. N. Saddler. 2009. Biotechnology Progress 25: $333 \sim 339$.

27. Kitts, W. D., J. G. Huffman, and C. R. Krishnamurti. 1971. Can. J. Anim. Sci. 51: 457.

28. Alizadeh, H., F. Teymouri, T. I. Gilbert, and B. 
Bon-Wook Koo, Ki-Seob Gwak, Ho-Yong Kim, Joon-Weon Choi, Hwanmyeong Yeo, and In-Gyu Choi

E. Dale. 2005. Applied Biochemistry and Biotechnology 124: $1133 \sim 1141$.

29. Holtzapple, M. T., J. H. Jun, G. Ashok, S. L. Patibandla, and B. E. Dale. 1991. Applied Biochemistry and Biotechnology 28: 59 74.

30. Iyer, P. V., Z. W. Wu, S. B. Kim, and Y. Y. Lee. 1996. Applied Biochemistry and Biotechnology 57: $121 \sim 132$.

31. Kim, T. H., J. S. Kim, C. Sunwoo, and Y. Y. Lee. 2003. Bioresource Technology 90: 39 47.

32. Kim, T. H. and Y. Y. Lee. 2005. Bioresource Technology 96: 2007 2013.

33. Teymouri, F., L. Laureano-Perez, H. Alizadeh, and B. E. Dale. 2005. Bioresource Technology 96: $2014 \sim 2018$.

34. Cheng, Y. S., J. VanderGheynst, Y. Zheng, R. Zhang, and B. Jenkins. 2009. in Eds, pp.

35. Grabber, J. H., R. D. Hatfield, F. Lu, and J. Ralph. 2008. Biomacromolecules 9: 2510 2516.

36. Liu, C. and C. E. Wyman. 2003. Ind. Eng. Chem. Res. 42: 5409 5416.

37. Caulfield, D. F. and W. E. Moore. 1973. Effect of varying crystallinity of cellulose on enzymic hydrolysis, Forest Products Laboratory, US Dept. of Agriculture.

38. Fan, L. T., M. M. Gharpuray, and Y. Lee. 1981. in Biotechnology \& Bioengineering Symposium Eds, pp. 29 45.

39. Laureano-Perez, L., F. Teymouri, H. Alizadeh, and B. E. Dale. 2005. Applied Biochemistry and Bio- technology 124: 1081 1099 .

40. Chang, V. S. and M. T. Holtzapple. 2000. in $21^{\text {st }}$ Symposium on Biotechnology for Fuels and Chemicals, Eds, pp. $84 \sim 86$.

41. Kasahara, K., H. Sasaki, N. Donkai, T. Yoshihara, and T. Takagishi. 2001. Cellulose 8: 23 28.

42. Tanahashi, M., T. Higuchi, S. Takada, T. Aoki, T. Goto, and S. Hanai. 1983. Wood Research 69: $36 \sim 51$.

43. Himmel, M. E., S. Y. Ding, D. K. Johnson, W. S. Adney, M. R. Nimlos, J. W. Brady, and T. D. Foust. 2007. Science 315: 804. 